\title{
EL CANÓNIGO EN CASTELLANO: \\ EN LA TRADICIÓN DE TRADUCCIÓN
}

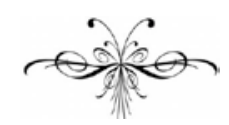

MACHAdo DE Assis

ROSARIO LÁZARO IGOA

LUZ AdRIANA SÁNCHEz SEGURA

\section{O CÔNEGO OU METAFÍSICA DO ESTILO}

— "VEM DO LÍBANO, esposa minha, vem do Líbano, vem... As mandrágoras, deram o seu cheiro. Temos às nossas portas toda casta de pombos..."

— "Eu vos conjuro, filhas de Jerusalém, que se encontrardes o meu amado, lhe façais saber que estou enferma de amor..."

Era assim, com essa melodia do velho drama de Judá, que procuravam um ao outro na cabeça do Cônego Matias um substantivo e um adjetivo... Não me interrompas, leitor precipitado; sei que não acreditas em nada do que vou dizer. Di-lo-ei, contudo, a despeito da tua pouca fé, porque o dia da conversão pública há de chegar.

Nesse dia, - cuido que por volta de 2222, — o paradoxo despirá as asas para vestir a japona de uma verdade comum. Então esta página merecerá,

\section{El CANÓNIGO O METAFÍSICA DEL ESTILO}

- "VEN DEL LÍBANO, Esposa mía, ven del Líbano, ven... Las mandrágoras han dado olor. Tenemos a nuestras puertas toda casta de palomas..."

- "Conjúroos, hijas de Jerusalém, si hallaréis á mi amado, que le aviseis, que de amor desfallezco...”

Era así, con esa melodía del viejo drama de Judá, que se buscaban uno a otro en la cabeza del Canónigo Matias un sustantivo y un adjetivo... No me interrumpas, lector precipitado; sé que no crees en nada de lo que te voy a decir. Te lo diré, no obstante, a despecho de tu poca fe, porque el día de la conversión pública ha de llegar.

Ese día, - estimo que alrededor de 2222, - la paradoja se despojará de sus alas para vestir el traje de una verdad común. Entonces esta página 
mais que favor, apoteose. Hão de traduzi-la em todas as línguas. As academias e institutos farão dela um pequeno livro, para uso dos séculos, papel de bronze, corte-dourado, letras de opala embutidas, e capa de prata fosca. Os governos decretarão que ela seja ensinada nos ginásios e liceus. As filosofias queimarão todas as doutrinas anteriores, ainda as mais definitivas, e abraçarão esta psicologia nova, única verdadeira, e tudo estará acabado.

Até lá passarei por tonto, como se vai ver.

Matias, cônego honorário e pregador efetivo, estava compondo um sermão quando começou o idílio psíquico. Tem quarenta anos de idade, e vive entre livros e livros para os lados da Gamboa. Vieram encomendar-lhe o sermão para certa festa próxima; ele que se regalava então com uma grande obra espiritual, chegada no último paquete, recusou o encargo; mas instaram tanto, que aceitou.

- Vossa Reverendíssima faz isto brincando, disse o principal dos festeiros.

Matias sorriu manso e discreto, como devem sorrir os eclesiásticos e os diplomatas. Os festeiros despediram-se com grandes gestos de veneração, e foram anunciar a festa nos jornais, com a declaração de que pregava ao Evangelho o Cônego Matias, "um dos ornamentos do clero brasileiro". Este "ornamento do clero" tirou ao cônego a vontade de almoçar, quando ele o leu agora de manhã; e só por estar ajustado, é que se meteu a escrever o sermão.

Começou de má vontade, mas no fim de alguns minutos já trabalhava com amor. A inspiração, com os olhos no céu, e a meditação, com os olhos no chão, ficam a um e outro lado do merecerá, más que favores, apoteosis. Habrán de traducirla a todas las lenguas. Las academias y los institutos harán de ella un pequeño libro, para el uso de los siglos, papel de bronce, corte dorado, letras de ópalo incrustadas, y tapa de plata opaca. Los gobiernos decretarán que sea impartida en los gimnasios y liceos. Las filosofías quemarán todas las doctrinas previas, incluso las más definitivas, y abrazarán esta psicología nueva, única verdadera, y todo estará acabado.

Hasta entonces pasaré por tonto, como se verá.

Matias, canónigo honorario y predicador efectivo, estaba componiendo un sermón cuando comenzó el idilio psíquico. Tiene cuarenta años, y vive entre libros y libros por los lados de Gamboa. Vinieron a encomendarle el sermón para cierta fiesta cercana; él que se regalaba en ese entonces con una gran obra espiritual, llegada en el último paquebote, recusó el encargo; pero instaron tanto que aceptó.

- Vuestra Reverendísima hace eso jugando, dijo el principal de los organizadores.

Matias sonrió manso y discreto, como deben sonreír los eclesiásticos y los diplomáticos. Los organizadores de la fiesta se despidieron con grandes gestos de veneración, y fueron a anunciar la fiesta en los periódicos, con la declaración de que predicaría el evangelio el Canónigo Matias, "uno de los ornamentos del clero brasileño". Este "ornamento del clero" le quitó al canónigo las ganas de almorzar, cuando lo leyó ahora en la mañana; y sólo por estar pactado, fue que se puso a escribir el sermón.

Comenzó de mala voluntad, pero después de algunos minutos ya trabajaba con amor. La inspiración, con los ojos en el cielo, y la meditación, con los ojos en el suelo, 
espaldar da cadeira, dizendo ao ouvido do cônego mil cousas místicas e graves. Matias vai escrevendo, ora devagar, ora depressa. As tiras saemlhe das mãos, animadas e polidas. Algumas trazem poucas emendas ou nenhumas. De repente, indo escrever um adjetivo, suspende-se; escreve outro e risca-o; mais outro, que não tem melhor fortuna. Aqui é o centro do idílio. Subamos à cabeça do cônego.

Upa! Cá estamos. Custou-te, não, leitor amigo? É para que não acredites nas pessoas que vão ao Corcovado, e dizem que ali a impressão da altura é tal, que o homem fica sendo cousa nenhuma. Opinião pânica e falsa, falsa como Judas e outros diamantes. Não creias tu nisso, leitor amado. Nem Corcovados, nem Himalaias valem muita cousa ao pé da tua cabeça, que os mede. Cá estamos. Olha bem que é a cabeça do cônego. Temos à escolha um ou outro dos hemisférios cerebrais; mas vamos por este, que é onde nascem os substantivos. Os adjetivos nascem no da esquerda. Descoberta minha, que ainda assim não é a principal, mas a base dela, como se vai ver. Sim, meu senhor, os adjetivos nascem de um lado, e os substantivos de outro, e toda a sorte de vocábulos está assim dividida por motivo da diferença sexual...

\section{- Sexual?}

Sim, minha senhora, sexual. As palavras têm sexo. Estou acabando a minha grande memória psico-léxicológica, em que exponho e demonstro esta descoberta. Palavra tem sexo. outras?

- Mas, então, amam-se umas às

Amam-se umas às outras. E casam-se. O casamento delas é o que chamamos estilo. Senhora minha, confesse que não entendeu nada.

— Confesso que não. quedan a un lado y otro del espaldar de la silla, diciéndole al oído del canónigo mil cosas místicas y graves. Matias va escribiendo, ora despacio, ora deprisa. Las tiras le salen de las manos, animadas y pulidas. Algunas traen pocas enmiendas o ninguna. De repente, yendo a escribir un adjetivo, se suspende; escribe otro y lo tacha; otro más, que no tiene mejor fortuna. Aquí es el centro del idilio. Subamos a la cabeza del canónigo.

¡Upa! Aquí estamos. Te costó, ¿no, lector amigo? Es para que no creas en las personas que van al Corcovado, y dicen que allá la impresión de la altura es tal, que el hombre queda siendo poca cosa. Opinión pánica y falsa como Judas y otros diamantes. No creas tú en eso, lector amado. $\mathrm{Ni}$ Corcovados, ni Himalayas valen mucha cosa al pie de tu cabeza, que los mide. Aquí estamos. Mira bien que es la cabeza del canónigo. Tenemos para escoger uno u otro de los hemisferios cerebrales; pero vamos por este, que es donde nacen los sustantivos. Los adjetivos nacen en el de la izquierda. Descubrimiento mío, que aun así no es el principal, sino su base, como se verá. Sí, mi señor, los adjetivos nacen de un lado, y los sustantivos de otro, y toda la suerte de vocablos está así divida por motivo de la diferencia sexual...

$$
\text { - ¿Sexual? }
$$

Sí, mi señora, sexual. Las palabras tienen sexo. Estoy acabando mi gran memoria psicoléxicológica, en que expongo y demuestro este descubrimiento. La palabra tiene sexo.

- Pero, entonces, ¿se aman unas a otras?

Se aman unas a otras. Y se casan. $\mathrm{Su}$ matrimonio es lo que llamamos estilo. Señora mía, confiese que no entendió nada.

- Confieso que no. 
Pois entre aqui também na cabeça do cônego. Estão justamente a suspirar deste lado. Sabe quem é que suspira? É o substantivo de há pouco, o tal que o cônego escreveu no papel, quando suspendeu a pena. Chama por certo adjetivo, que lhe não aparece: "Vem do Líbano, vem..." E fala assim, pois está em cabeça de padre; se fosse de qualquer pessoa do século, a linguagem seria a de Romeu: "Julieta é o sol... ergue-te, lindo sol." Mas em cérebro eclesiástico, a linguagem é a das Escrituras. Ao cabo, que importam fórmulas? Namorados de Verona ou de Judá falam todos o mesmo idioma, como acontece com o thaler ou o dólar, o florim ou a libra que é tudo o mesmo dinheiro.

Portanto, vamos lá por essas circunvoluções do cérebro eclesiástico, atrás do substantivo que procura o adjetivo. Sílvio chama por Sílvia. Escutai; ao longe parece que suspira também alguma pessoa; é Sílvia que chama por Sílvio.

Ouvem-se agora e procuram-se. Caminho difícil e intrincado que é este de um cérebro tão cheio de cousas velhas e novas! Há aqui um burburinho de idéias, que mal deixa ouvir os chamados de ambos; não percamos de vista o ardente Sílvio, que lá vai, que desce e sobe, escorrega e salta; aqui, para não cair, agarra-se a umas raízes latinas, ali abordoa-se a um salmo, acolá monta num pentâmetro, e vai sempre andando, levado de uma força íntima, a que não pode resistir.

De quando em quando, aparecelhe alguma dama - adjetivo também — e oferece-lhe as suas graças antigas ou novas; mas, por Deus, não é a mesma, não é a única, a destinada $a b$ eterno para este consórcio. E Sílvio vai andando, à procura da única. Passai, olhos de toda cor, forma de toda casta,
Pues entre aquí también a la cabeza del canónigo. Van justamente a suspirar a este lado. ¿Sabe quién es que suspira? Es el sustantivo de hace poco, ese que el canónigo escribió en el papel, cuando suspendió la pluma. Clama por cierto adjetivo, que no le aparece: "Ven del Líbano, ven..." Y habla así, pues está en cabeza de padre; si fuera de cualquier persona del siglo, el lenguaje sería el de Romeo: "Julieta es el sol... alza, bella lumbrera”. Pero en cerebro eclesiástico, el lenguaje es el de las Escrituras. Al cabo, ¿qué importan las fórmulas? Enamorados de Verona o de Judá hablan todos el mismo idioma, como ocurre con el tálero o el dólar, el florín o la libra que es todo el mismo dinero.

Por tanto, vamos por esas circunvoluciones del cerebro eclesiástico, atrás del sustantivo que busca al adjetivo. Sílvio clama por Sílvia. Escuchad; a lo lejos parece que suspira también alguna persona; es Sílvia que clama por Sílvio.

Se oyen ahora y se buscan. ¡Camino difícil e intrincado que es este de un cerebro tan lleno de cosas viejas y nuevas! Hay aquí un murmullo de ideas, que poco deja oír los llamados de ambos; no perdamos de vista al ardiente Sílvio, que allí va, que baja y sube, resbala y salta; aquí, para no caer, se agarra de unas raíces latinas, allí se apoya en un salmo, allá se monta en un pentámetro, y va siempre andando, llevado por una fuerza íntima, a la que no puede resistir.

De cuando en cuando, le aparece alguna dama - adjetivo también - y le ofrece sus gracias antiguas o nuevas; pero, por Dios, no es la misma, no es la única, la destinada $a b$ eterno a este consorcio. Y Sílvio va andando, en la búsqueda de la única. Pasad, ojos de todo color, forma de toda casta, 
cabelos cortados à cabeça do Sol ou da Noite; morrei sem eco, meigas cantilenas suspiradas no eterno violino; Sílvio não pede um amor qualquer, adventício ou anônimo; pede um certo amor nomeado e predestinado.

Agora não te assustes, leitor, não é nada; é o cônego que se levanta, vai à janela, e encosta-se a espairecer do esforço. Lá olha, lá esquece o sermão e o resto. O papagaio em cima do poleiro, ao pé da janela, repete-lhe as palavras do costume e, no terreiro, o pavão enfuna-se todo ao sol da manhã; o próprio sol, reconhecendo o cônego, manda-lhe um dos seus fiéis raios, a cumprimentá-lo. E o raio vem, e pára diante da janela: "Cônego ilustre, aqui venho trazer os recados do sol, meu senhor e pai." Toda a natureza parece assim bater palmas ao regresso daquele galé do espírito. Ele próprio alegra- se, entorna os olhos por esse ar puro, deixa-os ir fartarem-se de verdura e fresquidão, ao som de um passarinho e de um piano; depois fala ao papagaio, chama o jardineiro, assoa-se, esfrega as mãos, encosta-se. Não lhe lembra mais nem Sílvio nem Sílvia.

Mas Sílvio e Sílvia é que se lembram de si. Enquanto o cônego cuida em cousas estranhas, eles prosseguem em busca um do outro, sem que ele saiba nem suspeite nada. Agora, porém, o caminho é escuro. Passamos da consciência para a inconsciência onde se faz a elaboração confusa das idéias, onde as reminiscências dormem ou cochilam. Aqui pulula a vida sem formas, os germens e os detritos, os rudimentos e os sedimentos; é o desvão imenso do espírito. Aqui caíram eles, à procura um do outro, chamando e suspirando. Dê-me a leitora a mão, agarre-se o leitor a mim, e escorreguemos também. cabellos cortados a la cabeza del Sol o de la Noche; morid sin eco, tiernas cantilenas suspiradas en el eterno violín; Sílvio no pide un amor cualquiera, advenedizo o anónimo; pide un cierto amor designado y predestinado.

Ahora no te asustes, lector, no es nada; es el canónigo que se levanta, va hacia la ventana, y se recuesta para distraerse del esfuerzo. Allá mira, allá olvida el sermón y el resto. El loro encima de la estaca, al pie de la ventana, le repite las palabras de costumbre $\mathrm{y}$, en el patio, el pavo se hincha todo al sol de la mañana; el propio sol, reconociendo al canónigo, le manda uno de sus fieles rayos, a saludarlo. $\mathrm{Y}$ el rayo viene, $\mathrm{y}$ para frente a la ventana: "Canónigo ilustre, aquí vengo a traer los recados del sol, mi señor y padre”. Toda la naturaleza parece así aplaudir el regreso de aquella galera del espíritu. Él mismo se alegra, entorna los ojos por ese aire puro, los deja ir a hartarse de verdor y frescura, al son de un pajarito y de un piano; después le habla al loro, llama al jardinero, se suena, se refriega las manos, se recuesta. No evoca más ni a Sílvio ni a Sílvia.

Pero son Sílvio y Sílvia los que se evocan entre sí. Mientras el canónigo se ocupa de cosas extrañas, ellos prosiguen en busca uno del otro, sin que él sepa ni sospeche nada. Ahora, sin embargo, el camino es oscuro. Pasamos de la consciencia a la inconsciencia donde ocurre la elaboración confusa de las ideas, donde las reminiscencias duermen o hacen la siesta. Aquí pulula la vida sin formas, los gérmenes y los detritos, los rudimentos y los sedimentos; es el desván inmenso del espíritu. Aquí cayeron ellos, en busca uno del otro, clamando y suspirando. Deme la lectora la mano, agárrese el lector de mí, y resbalemos también. 
Vasto mundo incógnito. Sílvio e Sílvia rompem por entre embriões e ruínas. Grupos de idéias, deduzindo-se à maneira de silogismos, perdem-se no tumulto de reminiscências da infância e do seminário. Outras idéias, grávidas de idéias, arrastam-se pesadamente, amparadas por outras idéias virgens. Cousas e homens amalgamam-se; Platão traz os óculos de um escrivão da câmara eclesiástica; mandarins de todas as classes distribuem moedas etruscas e chilenas, livros ingleses e rosas pálidas; tão pálidas, que não parecem as mesmas que a mãe do cônego plantou quando ele era criança. Memórias pias e familiares cruzam-se e confundem-se. Cá estão as vozes remotas da primeira missa; cá estão as cantigas da roça que ele ouvia cantar às pretas, em casa; farrapos de sensações esvaídas, aqui um medo, ali um gosto, acolá um fastio de cousas que vieram cada uma por sua vez, e que ora jazem na grande unidade impalpável e obscura.

minha...

- Vem do Líbano, esposa

— Eu vos conjuro, filhas de Jerusalém...

Ouvem-se cada vez mais perto. Eis aí chegam eles às profundas camadas de teologia, de filosofia, de liturgia, de geografia e de história, lições antigas, noções modernas, tudo à mistura, dogma e sintaxe. Aqui passou a mão panteísta de Spinoza, às escondidas; ali ficou a unhada do Doutor Angélico; mas nada disso é Sílvio nem Sílvia. E eles vão rasgando, levados de uma força íntima, afinidade secreta, através de todos os obstáculos e por cima de todos os abismos. Também os desgostos hão de vir. Pesares sombrios, que não ficaram no coração do cônego, cá estão, à laia de manchas morais, e ao pé deles o reflexo amarelo ou roxo, ou o que quer
Vasto mundo incógnito. Sílvio y Sílvia irrumpen entre embriones y ruinas. Grupos de ideas, deduciéndose a manera de silogismos, se pierden en el tumulto de reminiscencias de la infancia y del seminario. Otras ideas, preñadas de ideas, se arrastran pesadamente, amparadas por otras ideas vírgenes. Cosas y hombres se amalgaman; Platón trae los anteojos de un escribano de la cámara eclesiástica; mandarines de todas las clases distribuyen monedas etruscas y chilenas, libros ingleses $\mathrm{y}$ rosas pálidas; tan pálidas, que no parecen las mismas que la madre del canónigo plantó cuando él era niño. Memorias pías y familiares se cruzan y se confunden. Aquí están las voces remotas de la primera misa; aquí están las cantigas del campo que les escuchaba cantar a las negras, en su casa; harapos de sensaciones desvaídas, aquí un miedo, allí un gusto, allá un hastío de cosas que vinieron una a una, y que ahora yacen en la gran unidad impalpable y oscura.

- Ven del Líbano, Esposa mía...

- Conjúroos, hijas de Jerusalém...

Se escuchan cada vez más cerca. Ahí llegan ellos a las profundas capas de teología, de filosofía, de liturgia, de geografía y de historia, lecciones antiguas, nociones modernas, todo mezclado, dogma y sintaxis. Aquí pasó la mano panteísta de Spinoza, a escondidas; allí quedó el rasguño del Doctor Angélico; pero nada de eso es Sílvio ni Sílvia. Y ellos van surcando, impulsados por una fuerza íntima, afinidad secreta, a través de todos los obstáculos y encima de todos los abismos. Incluso los disgustos habrán de venir. Pesares sombríos, que no quedaron en el corazón del canónigo, aquí están, a manera de manchas morales, y a sus pies el reflejo amarillo 
que seja da dor alheia e universal. Tudo isso vão eles cortando, com a rapidez do amor e do desejo.

Cambaleias, leitor? Não é o mundo que desaba; é o cônego que se sentou agora mesmo. Espaireceu à vontade, tornou à mesa do trabalho, e relê o que escreveu, para continuar; pega da pena, molha-a, desce-a ao papel, a ver que adjetivo há de anexar ao substantivo.

Justamente agora é que os dous cobiçosos estão mais perto um do outro. As vozes crescem, o entusiasmo cresce, todo o Cântico passa pelos lábios deles, tocados de febre. Frases alegres, anedotas de sacristia, caricaturas, facécias, disparates, aspectos estúrdios, nada os retém, menos ainda os faz sorrir. Vão, vão, o espaço estreita-se. Ficai aí, perfis meio apagados de paspalhões que fizeram rir ao cônego, e que ele inteiramente esqueceu; ficai, rugas extintas, velhas charadas, regras de voltarete, e vós também, células de idéias novas, debuxos de concepções, pó que tens de ser pirâmide, ficai, abalroai, esperai, desesperai, que eles não têm nada convosco. Amam-se e procuramse.

Procuram-se e acham-se. Enfim, Sílvio achou Sílvia. Viram-se, caíram nos braços um do outro, ofegantes de canseira, mas remidos com a paga. Unem-se, entrelaçam os braços, e regressam palpitando da inconsciência para a consciência. "Quem é esta que sobe do deserto, firmada sobre o seu amado?", pergunta Sílvio, como no Cântico; e ela, com a mesma lábia erudita, responde-lhe que "é o selo do seu coração", e que "o amor é tão valente como a própria morte". o violeta, o lo que quiera que sea del dolor ajeno y universal. Todo eso van ellos surcando, con la rapidez del amor y del deseo.

¿Tambaleas, lector? No es el mundo que se desmorona; es el canónigo que se sentó ahora mismo. Se distrajo un poco, volvió a la mesa de trabajo, y relee lo que escribió, para continuar; toma la pluma, la moja, la lleva al papel, a ver qué adjetivo habrá de anexar al sustantivo.

Justamente ahora es que los dos codiciosos están más cerca uno del otro. Las voces crecen, el entusiasmo crece, todo el Cantar pasa por sus labios, tocados por la fiebre. Frases alegres, anécdotas de sacristía, caricaturas, bromas, disparates, aspectos absurdos, nada los retiene, menos aún los hace sonreír. Van, van, el espacio se estrecha. Quedaos allí, perfiles medio difusos de zopencos que hicieron reír al canónigo, y que él por completo olvidó; quedaos, arrugas extinguidas, viejas charadas, reglas de tresillo, y vosotros también, células de ideas nuevas, esbozos de concepciones, polvo que has de ser pirámide, quedaos, amarraos, esperad, desesperad, que ellos no tienen nada que ver con vosotros. Se aman y se buscan.

Se buscan y se encuentran. Por fin, Sílvio encontró a Sílvia. Se vieron, cayeron uno en los brazos del otro, jadeantes de cansancio, pero redimidos con la paga. Se unen, entrelazan los brazos, y regresan palpitando de la inconsciencia a la consciencia. “QQuien es esta, que sube del desierto, apoyada sobre su amado?”, pregunta Sílvio, como en el Cantar; y ella, con la misma labia erudita, le responde que es el "sello de su corazón”, y que "fuerte es como la muerte el amor”. 
Nisto, o cônego estremece. O rosto ilumina-se-lhe. A pena cheia de comoção e respeito completa o substantivo com o adjetivo. Sílvia caminhará agora ao pé de Sílvio, no sermão que o cônego vai pregar um dia destes, e irão juntinhos ao prelo, se ele coligir os seus escritos, o que não se sabe.
Entonces, el canónigo se estremece. El rostro se le ilumina. La pluma llena de conmoción y respeto completa el sustantivo con el adjetivo. Sílvia caminará ahora al pie de Sílvio, en el sermón que el canónigo va a pregonar un día de estos, e irán junticos a la imprenta, si reúne sus escritos, lo que no se sabe.

FIM

FIN

$\mathrm{H}_{\mathrm{y}}^{\mathrm{y}}$ l creciente interés del mundo académico brasileño por la suerte crítica y traductiva en el exterior de uno de sus más reconocidos escritores, Joaquim Maria Machado de Assis, habilita iniciativas como esta, en la cual una propuesta de traducción de un cuento de su autoría oficia de puntapié para problematizar por medio de la práctica su lugar dentro de la lengua castellana. Una propuesta que trae implícita, además, la idea de la pervivencia de las obras por medio de la traducción, la sobrevida que Walter Benjamin propuso en su ensayo "Die Aufgabe des Übersetzers", de 1923, y que se materializa en este caso por medio de numerosas traducciones a distintas lenguas. Al mismo tiempo, por tratarse de una publicación dentro del ámbito académico, permite un posicionamiento distinto del traductor, traductoras en esta ocasión, para entonces esbozar un plan de traducción no signado por requerimientos editoriales inmediatos, sino más bien por las características del texto a ser traducido, las necesidades del presente de las lenguas que se pondrán en contacto y las discusiones académicas vigentes dentro de los Estudios de la Traducción en el Siglo XXI.

No menos importante es el aspecto lúdico de la tarea y sus desafíos: ¿cómo serán las demás traducciones? ¿Habrá otras en castellano? ¿Cuáles serán las líneas de trabajo de nuestros colegas traductores? ¿Qué Machado estaremos construyendo en este mosaico de nuevas traducciones de "O Cônego ou Metafísica do Estilo"? Estas preguntas, llevadas a un trabajo a cuatro manos, hacen más desafiante la iniciativa emprendida. Como dijimos en el párrafo anterior, promueven la diferencia, la no univocidad del original hacia una sola traducción posible, la complementación entre las miradas lanzadas sobre este cuento de Machado. Volviendo a Benjamin, por cierto, esto nos lleva a preguntarnos acerca del objetivo de la traducción:

E uma tradução? Será ela dirigida a leitores que não compreendem o original? Essa questão parece explicar suficientemente a diferença de estatura entre ambos no âmbito da arte. Além disso, parece ser este o único motivo possível para se dizer "a mesma coisa” repetidas vezes. O que "diz” uma obra poética? O que comunica? Muito pouco para quem a compreende. O que lhe é essencial não é a comunicação, não é o enunciado. (BENJAMIN, 2010, p. 203) 
En suma, nos interesa realizar una traducción orientada por una lectura de la obra literaria como tal, como forma, considerándola como no signada de manera intrínseca por sus condiciones de creación, o por las características de la futura recepción. La tarea, esta tarea de traducción, será signada por el deseo de continuar su sobrevida, su capacidad de vivir en la traducción.

"O Cônego ou Metafísica do Estilo" no es un cuento eminentemente signado por su contexto histórico (aunque obviamente tenga rasgos suyos), ni tampoco por elementos culturales que se transformen en tema de la narrativa, en elemento constitutivo de la misma. Por el contrario, estamos frente a un cuento en el que los elementos psicológicos son los que marcan el desarrollo de los hechos, en que la acción se juega dentro de la mente del individuo, el Canónigo Matias, quien se ha comprometido a escribir un sermón. Pero ello no quiere decir que la traducción sea menos desafiante, ya que de todas maneras los rasgos de la obra son otros, como veremos más adelante.

\section{Tradición de traducción}

El cuento “O Cônego ou Metafísica do Estilo” apareció por primera vez en 1885 en la Gazeta de Notícias, y fue reunido en forma de libro en 1896, bajo el título Várias Histórias. Para la traducción, utilizamos la versión digitalizada del cuento disponible en la página del portal brasileño Domínio Público. ${ }^{1}$ Tuvimos acceso también a una edición de Garnier de 1904, disponible en la Open Library, de la UNESCO, ${ }^{2}$ donde pudimos advertir la ortografía antigua y los ajustes posteriores que el cuento ha tenido en las sucesivas ediciones en portugués. Ahora bien, al tratarse de un cuento traducido previamente al castellano, una vez concluida nuestra traducción, realizamos una consulta de sus traducciones anteriores, con el fin de observar cuáles habían sido los proyectos por detrás de tales emprendimientos y de articularlos con nuestro trabajo. Nos interesaba situar nuestra traducción en relación a las que la antecedieron y que, de una forma u otra, han instaurado una cierta "tradición” de traducción de este cuento de Machado de Assis.

Según este pequeño relevamiento, registramos seis traducciones del cuento al castellano hasta nuestros días. Faltaría analizar, por ejemplo, antologías no organizadas por Machado que hayan sido traducidas sin el título de Varias Historias, y que contengan el cuento en cuestión, como por ejemplo la antología preparada por Alfredo Bosi, que veremos más adelante y a la que sí tuvimos acceso. A continuación, ofrecemos una tabla no exhaustiva de las traducciones que detectamos:

\begin{tabular}{|l|l|}
\hline 1911 & s/d. In: Varias historias. Paris: Garnier. Traducción de Rafael Mesa López. \\
\hline 1972 & $\begin{array}{l}\text { “El canónigo; o, Metafísica del estilo”. In: Varias historias. La Habana: Casa } \\
\text { de las Américas. Sin datos de traductor. }\end{array}$ \\
\hline 1985 & $\begin{array}{l}\text { "El canónigo o Metafísica del estilo”. In: Cuentos. Caracas: Biblioteca } \\
\text { Ayacucho. Traducción de Santiago Kovadloff. Prólogo y selección de }\end{array}$ \\
\hline
\end{tabular}

\footnotetext{
$1<$ http://www.dominiopublico.gov.br/pesquisa/DetalheObraForm.do?select_action=\&co_obra= 1983> [01/10/2013]

${ }^{2}<$ http://archive.org/stream/variashistorias00assigoog\#page/n283/mode/2up> [01/10/2013]
} 


\begin{tabular}{|l|l|}
\hline 1993 & Alfredo Bosi. \\
\hline 2007 & $\begin{array}{l}\text { "El CANóxico: Porrúa. Sin datos de traductor. Prólogo de Ilán Stavans. } \\
\text { cuentos. Quito: Libresa. Traducción de Remy Gorga Filho. }\end{array}$ \\
\hline 2012 & $\begin{array}{l}\text { "El canónigo o Metafísica del estilo". In: Varias historias. Montevideo: Cruz } \\
\text { del Sur. Organización y traducción de Pablo Cardellino Soto. }\end{array}$ \\
\hline
\end{tabular}

La primera de las traducciones, publicada en 1911, en París, por la editorial Garnier Hermanos, fue elaborada por Rafael Mesa López, traductor de otras obras de Machado de Assis, entre las que cabe destacar Dom Casmurro, publicada por la misma casa editorial en 1910. Las informaciones sobre la trayectoria de Mesa López son escasas, encontramos su nombre referenciado en Books in Brazil: A History of the Publishing Trade (1975) de Laurence Hallewell, traducido al portugués por primera vez en 1982, bajo el título O livro no Brasil: sua história. Su nombre aparece registrado en el capítulo décimo, titulado "Hippolyte Garnier”, en que Hallewell acompaña el proceso de expansión de la editorial Garnier y sus repercusiones en la difusión de la literatura brasileña, tras la muerte de Baptiste Louis Garnier, fundador de la sucursal de la editorial Garnier Frères en Brasil. En dicho capítulo se destaca la actuación de Hippolyte Garnier en lo que respecta a las traducciones de autores brasileños en castellano y francés, así como la política de compra y venta de derechos autorales. Es preciso aclarar que no tuvimos acceso a esta primera traducción. Según se nos informó, existe una segunda traducción de 1919 de Rafael Cansinos-Assens, a la que tampoco tuvimos acceso. ${ }^{3}$

La tercera traducción salió a la luz cincuenta años después, en Cuba. La editorial Casa de las Américas publicó en 1972 el libro de cuentos Varias Historias. No contamos con detalles de esta traducción debido a que no pudimos tener contacto directo con el libro; desconocemos la identidad de su(s) traductor(es) así como la existencia de cualquier tipo de posicionamiento frente a su tarea traductora.

En 1978, aparece la tercera traducción de "O Cônego ou Metafísica do Estilo” en castellano, dentro del volumen titulado Cuentos, preparado por Alfredo Bosi para la editorial Ayacucho. Este libro, que incluye un estudio preliminar escrito por Bosi, una cronología y una rica bibliografía crítica, fue traducido en su totalidad por Santiago Kovadloff (1942). A quien trabaja en el ámbito de la literatura traducida del portugués al castellano, el nombre de este traductor le es bastante familiar, pues su trayectoria es amplísima e incluye los nombres de grandes autores de origen brasileño y portugués, dentro de los que apenas destacamos aquí a poetas como Carlos Drummond de Andrade, Manuel Bandeira, Vinicius de Moraes, Mário de Andrade, Fernando Pessoa; y narradores como Machado de Assis y Guimarães Rosa.

Pese a que no tuvimos acceso a la edición impresa de este libro, pudimos acceder al texto íntegro digitalizado, ofrecido por la propia Biblioteca Ayacucho en su sitio web, y, por tanto, podremos hacer algunos comentarios específicos sobre la traducción del cuento que nos ocupa.

\footnotetext{
${ }^{3}$ Agradecemos a Pablo Cardellino Soto la información.
} 
Para comenzar es preciso decir que no aparecen en el libro justificaciones sobre las opciones del traductor y que, específicamente en el cuento que nos ocupa, no hay marcas explícitas de su presencia. Sin embargo, sus decisiones son evidentes en una lectura simultánea con el texto original. Una de esas decisiones, probablemente la más dominante, es la traducción del tratamiento en segunda persona del plural por la tercera:

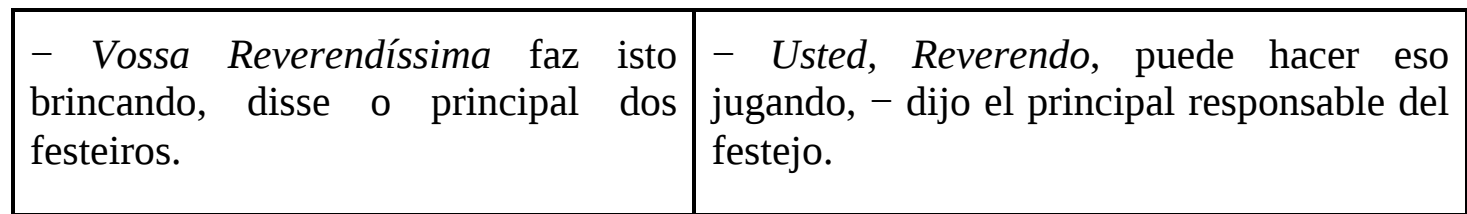

Otra situación en la que se revela su presencia es en el uso de palabras sinónimas en casos en que en castellano y en portugués las palabras comparten el sentido y tienen una grafía casi exacta. Veamos algunos ejemplos:

\begin{tabular}{|c|c|}
\hline $\begin{array}{l}\text { "ele que se regalava então com uma } \\
\text { grande obra espiritual” }\end{array}$ & $\begin{array}{l}\text { "él, que entonces se regodeaba con una } \\
\text { gran obra espiritual” }\end{array}$ \\
\hline "Matias sorriu manso e discreto" & "Matías sonrió plácido y discreto" \\
\hline $\begin{array}{l}\text { "um dos ornamentos do clero } \\
\text { brasileiro" }\end{array}$ & "uno de los oropeles del clero brasileño" \\
\hline $\begin{array}{l}\text { "e oferece-lhe as suas graças antigas } \\
\text { ou novas" }\end{array}$ & $\begin{array}{l}\text { "que le ofrece sus encantos antiguos os } \\
\text { nuevos" }\end{array}$ \\
\hline "cá estão as cantigas da roça” & “acá están las coplas de la tierra” \\
\hline $\begin{array}{l}\text { "Justamente agora é que os dous } \\
\text { cobiçosos estão mais perto um do } \\
\text { outro." }\end{array}$ & $\begin{array}{l}\text { "Justamente ahora es que los dos } \\
\text { anhelantes están más cerca uno del otro" }\end{array}$ \\
\hline
\end{tabular}

Hay también algunas frases en que la sintaxis es bastante modificada. Cabe decir, a propósito, que en el cuento hay oraciones muy largas, caracterizadas por la subordinación y, en ocasiones, una puntuación que, aunque sistemática, puede generar extrañeza en el lector. Consideremos apenas tres ejemplos:

\begin{tabular}{|c|c|}
\hline $\begin{array}{l}\text { “A inspiração, com os olhos no céu, e } \\
\text { a meditação, com os olhos no chão, } \\
\text { ficam a um e outro lado do espaldar } \\
\text { da cadeira, dizendo ao ouvido do } \\
\text { cônego mil cousas místicas e graves” }\end{array}$ & $\begin{array}{l}\text { "La inspiración, con los ojos puestos en el } \\
\text { cielo, y la meditación, con los ojos en el } \\
\text { suelo, se ubican a uno y otro lado del } \\
\text { respaldo de la silla, susurrando a los oídos } \\
\text { del canónigo mil cosas místicas y graves." }\end{array}$ \\
\hline $\begin{array}{l}\text { "Estão justamente a suspirar deste } \\
\text { lado. Sabe quem é que suspira?” }\end{array}$ & $\begin{array}{l}\text { “Están justamente suspirando de este lado. } \\
\text { ¿Sabe quién es el que sobre todo suspira?” }\end{array}$ \\
\hline $\begin{array}{l}\text { "Dê-me a leitora a mão, agarre-se o } \\
\text { leitor a mim, e escorreguemos }\end{array}$ & $\begin{array}{l}\text { "Deme lectora su mano, tómese de mí el } \\
\text { lector, y deslicémonos también." }\end{array}$ \\
\hline
\end{tabular}


também.”

Encontramos otras de sus huellas en algunas oraciones en que hace pequeños cambios, como insertar o eliminar artículos y hacer ampliaciones que parecen sugerir la necesidad de descartar cualquier ambigüedad.

\begin{tabular}{|l|l|}
\hline $\begin{array}{l}\text { “...e dizem que ali a impressão da } \\
\text { altura é tal, que o homem fica sendo } \\
\text { cousa nenhuma.” }\end{array}$ & $\begin{array}{l}\text { “..y dicen que allí la impresión de altura es } \\
\text { insignificante.” }\end{array}$ \\
\hline “Sim, minha senhora, sexual.” & \begin{tabular}{l} 
“Sí, señora, sexual.” \\
\hline $\begin{array}{l}\text { “...ao som de um passarinho e de um } \\
\text { piano...” }\end{array}$
\end{tabular} $\begin{array}{l}\text { “...oye el trino de un pájaro y el fraseo de } \\
\text { un piano...” }\end{array}$ \\
\hline
\end{tabular}

Cabe observar cómo esas pequeñas modificaciones repercuten en la comprensión del texto y en dos de las traducciones posteriores. Nótese, por ejemplo, cómo se modifica el tono coloquial de la afirmación "Sim, minha senhora..." con la eliminación del pronombre posesivo; así como en el caso de la modificación del artículo "o" por el determinante "un" en la sentencia "o homem fica sendo cousa nenhuma”. Así mismo, obsérvese cómo se caracteriza el sonido del pájaro y del piano. Ese tipo de soluciones nos sugieren preguntas acerca de las motivaciones específicas del traductor y, por tanto, de la imagen del texto que pretendía proyectar en la traducción. Y esto es aún más destacable en la medida en que percibimos que son opciones apropiadas en dos de las traducciones posteriores.

\begin{tabular}{|c|c|c|}
\hline Santiago Kovadloff & Remy Gorga, filho & Pablo Cardellino Soto \\
\hline $\begin{array}{l}\text { “...y dicen que allí la } \\
\text { impresión de altura es } \\
\text { tal, que un hombre } \\
\text { termina } \\
\text { insignificante." }\end{array}$ & $\begin{array}{l}\text { “...y dicen que allí la } \\
\text { impresión de la altura es } \\
\text { tal que el hombre } \\
\text { termina } \\
\text { insignificante.” }\end{array}$ & $\begin{array}{l}\text { “...y dicen que allí la } \\
\text { impresión de la altura es tal, } \\
\text { que el hombre resulta } \\
\text { insignificante” }\end{array}$ \\
\hline $\begin{array}{l}\text { “..oye el trino de un } \\
\text { pájaro y el fraseo de un } \\
\text { piano..." }\end{array}$ & $\begin{array}{l}\text { "oye el trino de un } \\
\text { pajarito y el fraseo de un } \\
\text { piano..." }\end{array}$ & $\begin{array}{l}\text { “...oyendo un pajarito o un } \\
\text { piano...” }\end{array}$ \\
\hline
\end{tabular}

Lamentablemente, no tuvimos acceso a la cuarta traducción de 1993, realizada en México por la editorial Porrúa. Sabemos que el prólogo fue de Ilán Stavans, pero no pudimos acceder a los datos sobre el traductor (presumiblemente el mismo prologuista). Sin embargo, sí accedimos a la quinta traducción, publicada en 2007 en Ecuador. En tal año sale por la editorial Libresa el volumen de cuentos $L a$ iglesia del diablo y otros cuentos, con traducción de Remy Gorga, filho, donde encontramos “El Canónigo o metafísica del estilo”. En este sentido, la traducción 
realizada por Remy Gorga, filho está marcada por la profusión de notas a pie de página, notas que no son relativas a cuestiones culturales "intraducibles", sino a asuntos de conocimiento general, como "mandrágoras", "Judas Iscariote", "Himalaya", "silogismo". En el prólogo, titulado "Estudio introductorio o nota preliminar”, también de su autoría, hay un paralelismo cronológico vida-obra de Machado de Assis, repitiendo una maniobra usual de la crítica brasileña de postular lo biográfico como posibilidad de explicación de la obra, colocando lado a lado las obras con los hechos significativos de la vida del escritor. Al mismo tiempo, como justificación de la traducción de Machado al castellano, postula la supranacionalidad de sus temas, un escritor que tal vez podría no ser estrictamente brasileño.

La justificación de las decisiones de Gorga, filho parece esquiva en el texto, sobre todo por las evidencias de cierta desarticulación entre unas soluciones y otras. Notamos, por ejemplo, su preocupación por mantener el tratamiento en la segunda persona del plural en el caso de:

\begin{tabular}{|l|l|l|l|}
\hline $\begin{array}{l}\text { “- Vossa Reverendíssima faz isto } \\
\text { brincando” }\end{array}$ & $\begin{array}{l}\text { “- Vuestra Reverendísima hace eso } \\
\text { jugando” }\end{array}$ \\
\hline
\end{tabular}

como un gesto por mantener el registro del texto original, sin embargo, más adelante, sin que sea necesario demarcar la persona de la conjugación, incluye un pronombre asociado a la tercera persona:

"Cônego ilustre, aqui venho trazer os recados do sol, meu senhor e pai."

"Canónigo ilustre, aquí vengo a traerle los mensajes del Sol, mi señor y padre.”

Al mismo tiempo, como un movimiento -que podemos intuir- asociado a la necesidad de conservar la temporalidad de la lengua del texto original, opta por traducir palabras de uso común en portugués por palabras que en castellano tienen un uso muchísimo menos frecuente.

Veamos un ejemplo de lo anterior:

\begin{tabular}{|l|l|}
\hline $\begin{array}{l}\text { “... o próprio sol, reconhecendo o } \\
\text { cônego, manda-lhe um dos seus fiéis } \\
\text { raios, a cumprimentá-lo.”. el propio Sol, a su vez, reconociendo el } \\
\text { canónigo, le envía uno de sus fieles rayos, } \\
\text { para cumplimentarlo.” }\end{array}$ \\
\hline
\end{tabular}

Aprovechando el ejemplo que acabamos de referir, cabe anotar que percibimos en varias ocasiones problemas de concordancia preposicional posiblemente asociados al intento de imitar las estructuras del texto original. Nótese que mientras que en portugués el verbo "reconhecer" no exige preposición al estar vinculado con un objeto directo de persona, en castellano requiere la preposición "a" -reconocer a alguien- o el uso del pronombre -reconocerte/ reconocerlo / reconocerse, etc.- ${ }^{-}$Y, por tanto, la traducción de dicha oración exigiría el uso de la contracción "al": "reconociendo al canónigo". Veamos otros ejemplos asociados:

\begin{tabular}{|l|l|}
\hline $\begin{array}{l}\text { “... e vive entre livros e livros para os } \\
\text { lados da Gamboa.” }\end{array}$ & $\begin{array}{l}\text { “.. y vive entre libros y libros para los } \\
\text { lados de Gamboa.” }\end{array}$ \\
\hline
\end{tabular}




\begin{tabular}{|l|l|}
\hline $\begin{array}{l}\text { “...com a declaração de que pregava } \\
\text { ao Evangelho o Cônego Matias...” }\end{array}$ & $\begin{array}{l}\text { “... con la declaración de que predicaría al } \\
\text { Evangelio el Canónigo Matías...” }\end{array}$ \\
\hline $\begin{array}{l}\text { "Estão justamente a suspirar deste } \\
\text { lado.” }\end{array}$ & “Están justamente al suspirar de este lado” \\
\hline “... acolá monta num pentâmetro...” & “más allá monta $a$ un pentámetro” \\
\hline
\end{tabular}

Estos pocos ejemplos dan muestra no sólo de la falta de concordancia entre los verbos y las preposiciones, sino también de la dificultad de traducir construcciones como "Estão justamente a suspirar deste lado" y de su consecuente ilegibilidad en la traducción.

Cabe también anotar que esta traducción asimila varias de las soluciones propuestas por Kovadloff, destacadas anteriormente. Entre ellas, puede referirse la opción por palabras sinónimas - “regodeaba”, “encantos”, “adventicio”, "ensoberbece" -, y por expresiones como "el hombre termina siendo insignificante”, y "oye el trino de un pajarito y el fraseo de un piano", anteriormente citadas.

Ya en nuestra década, encontramos la traducción de Pablo Cardellino Soto ${ }^{4}$ para la editorial uruguaya Cruz del Sur, publicada en 2012 con apoyo de la Fundación Biblioteca Nacional de Brasil. Se trata de una traducción cuidadosa, que revela la existencia de una política clara y coherente a través de sus soluciones. Observamos un esfuerzo por caracterizar la lengua del cuento, es decir, por conservar ciertas marcas de su temporalidad a través del uso de palabras de uso menos frecuente en la actualidad - tales como “empero” y “acullá” - y la reconstrucción de expresiones que pueden parecer extrañas o equivocadas, hasta para un lector brasileño. Veamos un ejemplo de dicha reconstrucción:

\begin{tabular}{|l|l|}
\hline $\begin{array}{l}\text { “...onde se faz a elaboração confusa } \\
\text { das idéias...” }\end{array}$ & $\begin{array}{l}\text { “...donde se hace la elaboración confusa de } \\
\text { ideas...” }\end{array}$ \\
\hline
\end{tabular}

Se percibe también que, así como el traductor intenta conservar dicha temporalidad, sitúa su texto en una determinada variante del castellano, la rioplatense. Ese interés se revela en pequeños detalles, tales como el uso del verbo "sacar”, en vez de “quitar", para traducir "tirar”. Veamos el verbo en contexto:

\begin{tabular}{|c|c|}
\hline $\begin{array}{l}\text { “Este 'ornamento do clero’ tirou ao } \\
\text { cônego a vontade de almoçar...” }\end{array}$ & $\begin{array}{l}\text { “Este 'ornamento del clero’ le sacó al } \\
\text { canónigo las ganas de almorzar...” }\end{array}$ \\
\hline
\end{tabular}

En lo que se refiere al vocabulario, observamos cierta afinidad con algunas de las soluciones propuestas por Kovadloff, como el uso de palabras como "regodeaba” y “adventicio", y de algunas expresiones como "el hombre resulta insignificante”, comentadas anteriormente.

Aún dentro de las consideraciones sobre el vocabulario, creemos pertinente anotar el uso de dos palabras diferentes - "llamar" y "clamar" - para traducir el verbo "chamar" que aparece cuatro veces a lo largo del texto. Se trata de un recurso

\footnotetext{
${ }^{4}$ Agradecemos la disposición del traductor para enviarnos la versión digitalizada del cuento.
} 
diferente al usado en las traducciones de Kovadloff y Gorga, filho, que optan por el uso de solamente una de ellas, “clamar” y "llamar”, respectivamente.

\begin{tabular}{|c|c|}
\hline $\begin{array}{l}\text { "Chama por certo adjetivo, que lhe } \\
\text { não aparece..." }\end{array}$ & "Llama a cierto adjetivo, que no aparece" \\
\hline "Sílvio chama por Sílvia” & “Silvio clama por Silvia” \\
\hline "é Sílvia que chama por Sílvio" & "es Silvia que clama por Silvio" \\
\hline $\begin{array}{l}\text { "Aqui caíram eles, à procura um do } \\
\text { outro, chamando e suspirando.” }\end{array}$ & $\begin{array}{l}\text { "Aquí cayeron ellos, en busca uno del otro, } \\
\text { clamando y suspirando." }\end{array}$ \\
\hline
\end{tabular}

A pesar de que la elección de dichas palabras y la adjudicación de cada una de ellas para sujetos diferentes - el sustantivo de una parte, y Sílvio y Sílvia de otra parece responder a un interés del traductor, se evidencia un cambio significativo en el sentido del primer ejemplo. Nótese que la modificación de la preposición tiene implicaciones sobre la acción que se describe, que no es más el llamado de algo o alguien "por" algo o alguien, digamos, una invocación o una apelación, sino apenas un llamado "a”, es decir, una acción que recae sobre un sujeto específico y que no tiene en cuenta la fuerza deseante que sugiere el texto original.

\section{Nuestra traducción}

Como establecimos al comienzo de este texto, el marco teórico a partir del cual realizamos la traducción del cuento "O Cônego ou Metafísica do Estilo" fue el ensayo de Benjamin sobre la "tarea/renuncia" del traductor. Como resultado, tomamos varias decisiones relativas a un proyecto de traducción que tuviera este ensayo como norte conceptual. Una vez que decidimos que la variante del castellano elegida sería la colombiana, teniendo en cuenta la ausencia de traducciones para este sistema literario específico, la lectura del cuento en detalle permitió tomar la primera decisión con relación a las características del texto en sí. Por lo tanto, decidimos como punto básico tratar de una manera cuidadosa la sintaxis machadiana, tensarla al máximo en su pasaje al castellano, y no ceder a la tendencia bastante usual de reorganizar, o normalizar, este aspecto del original. Citamos algunos ejemplos de este aspecto de nuestra traducción, donde el orden de la sintaxis en castellano termina siendo inusual:

\begin{tabular}{|l|l|}
\hline $\begin{array}{l}\text { “Era assim, com essa melodia do } \\
\text { velho drama de Judá, que procuravam }\end{array}$ & $\begin{array}{l}\text { "Era así, con esa melodía del viejo drama } \\
\text { de Judá, que se buscaban uno a otro en la } \\
\text { um ao outro na cabeça do Cônego } \\
\text { cabeza del Canónigo Matías un sustantivo y } \\
\text { Matias um substantivo e um adjetivo...”. } \\
\text { adjetivo...”. }\end{array}$ \\
\hline $\begin{array}{l}\text { “Este 'ornamento do clero' tirou ao } \\
\text { cônego a vontade de almoçar, quando } \\
\text { ele o leu agora de manhã; e só por } \\
\text { estar ajustado, é que se meteu a } \\
\text { escrever o sermão”. }\end{array}$ & $\begin{array}{l}\text { canónigo las ganas de almorzar, cuando lo } \\
\text { leyó ahora en la mañana; y sólo por estar } \\
\text { pactado, fue que se puso a escribir el } \\
\text { sermón”. }\end{array}$ \\
\hline
\end{tabular}




\begin{tabular}{|l|l|}
\hline $\begin{array}{l}\text { “Justamente agora é que os dois } \\
\text { cobiçosos estão mais perto um do } \\
\text { outro". }\end{array}$ & $\begin{array}{l}\text { "Justamente ahora es que los dos codiciosos } \\
\text { están más cerca uno del otro". }\end{array}$ \\
\hline $\begin{array}{l}\text { "Ficai á, perfis meio apagados de } \\
\text { paspalhões que fizeram rir ao cônego, } \\
\text { e que ele inteiramente esqueceu (...)" }\end{array}$ & $\begin{array}{l}\text { Quedaos allí, perfiles medio difusos de } \\
\text { que él por completo olvidó (...)” }\end{array}$ \\
\hline
\end{tabular}

En consonancia con este respeto por la sintaxis, consideramos interesante un pasaje en particular: "Não lhe lembra mais nem Sílvio nem Sílvia./ Mas Sílvio e Sílvia é que se lembram de si”, que fue traducido como "No evoca más ni a Sílvio ni a Sílvia./ Pero son Sílvio y Sílvia los que se evocan entre sí”. Esta decisión fue fruto de considerar que "acordarse" o "recordar" no respondían por completo a "não lhe lembra mais", que parece no solo relacionado a recordar, sino también a la capacidad de convocar, llamar, evocar. Además, el verbo "evocar” es capaz de reproducir el efecto de la segunda parte del texto: "Pero son Sílvio y Sílvia los que se evocan entre sí”. Por otra parte, tradujimos una respuesta con la misma estructura que el portugués, de manera de "trasplantarla" al castellano y mantener su ritmo:

\begin{tabular}{|c|c|}
\hline $\begin{array}{l}\text { Senhora minha, confesse que não } \\
\text { entendeu nada. } \\
\text { - Confesso que não. }\end{array}$ & $\begin{array}{l}\text { Señora mía, confiese que no entendió nada. } \\
\text { - Confieso que no. }\end{array}$ \\
\hline
\end{tabular}

Una excepción a esta decisión relativa a la sintaxis fue la adición del artículo "la” en la traducción de "Palavra tem sexo", como "La palabra tiene sexo".

Otro de los elementos claves del texto es la referencia intertextual al Cantar de los Cantares, que sirve como dimensión religiosa y mística, al tiempo que también sensual, de la acción entre el sustantivo y el adjetivo dentro de la mente del canónigo. Al decidir qué Biblia utilizar para los pasajes con referencias bíblicas, consideramos necesario trabajar con una traducción de la misma que fuera contemporánea del cuento, no tanto por una razón de localización histórica específica, sino por la reconstrucción al interior del texto de la compleja red de referencias intertextuales y de las particularidades de la traducción elegida por Machado. Además, nos pareció importante que la Biblia elegida, que terminó siendo la traducida de la Vulgata al castellano por Felipe Scio de San Miguel y publicada en 1793 como La Biblia Sagrada, coincidiera en sus elecciones con la usada por Machado, razón por la cual descartamos la traducción del Cantar de los Cantares, de Fray Luis de León, traducción netamente distinta a la que el autor refiere.

Para las citas del Cantar de los Cantares, dejamos la ortografía original de la traducción del Siglo XVIII, sin alterarla, aunque sí realizamos algunos ajustes para que fueran coincidentes con el cuento en portugués, sobre todo en lo que refiere a una supresión en un caso puntual, como mostramos en el cuadro que sigue: 


\begin{tabular}{|c|c|c|c|}
\hline Texto en portugués & Versículo & $\begin{array}{l}\text { Traducción de Felipe } \\
\text { Scio de San Miguel }\end{array}$ & $\begin{array}{l}\text { Citas en nuestra } \\
\text { traducción }\end{array}$ \\
\hline $\begin{array}{l}\text { "VEM DO LÍBANO, } \\
\text { esposa minha, vem do } \\
\text { Líbano, vem..." }\end{array}$ & 4.8 & $\begin{array}{l}\text { "Ven del Líbano, } \\
\text { Esposa mía, ven del } \\
\text { Líbano, ven }(. . .) \text { " }\end{array}$ & $\begin{array}{l}\text { "Ven del Líbano, } \\
\text { Esposa mía, ven del } \\
\text { Líbano, ven..." }\end{array}$ \\
\hline $\begin{array}{l}\text { "As mandrágoras, } \\
\text { deram o seu cheiro" }\end{array}$ & 7.13 & $\begin{array}{l}\text { "Las mandrágoras han } \\
\text { dado olor" }\end{array}$ & $\begin{array}{l}\text { "Las mandrágoras han } \\
\text { dado olor" }\end{array}$ \\
\hline $\begin{array}{l}\text { "Eu vos conjuro, filhas } \\
\text { de Jerusalém, que se } \\
\text { encontrardes o meu } \\
\text { amado, lhe façais saber } \\
\text { que estou enferma de } \\
\text { amor..." }\end{array}$ & 5.8 & $\begin{array}{l}\text { "Conjúroos, hijas de } \\
\text { Jerusalém, si hallareis } \\
\text { á mi amado, que le } \\
\text { aviseis, que de amor } \\
\text { desfallezco..." }\end{array}$ & $\begin{array}{l}\text { "Conjúroos, hijas de } \\
\text { Jerusalém, si hallareis } \\
\text { á mi amado, que le } \\
\text { aviseis, que de amor } \\
\text { desfallezco..." }\end{array}$ \\
\hline $\begin{array}{l}\text { "Quem é esta que sobe } \\
\text { do deserto, firmada } \\
\text { sobre o seu amado?" }\end{array}$ & 8.5 & $\begin{array}{l}\text { “QQuien es esta, que } \\
\text { sube del desierto, } \\
\text { llena de delicias, } \\
\text { apoyada sobre su } \\
\text { amado?” }\end{array}$ & $\begin{array}{l}\text { “Quien es esta, que } \\
\text { sube del desierto, } \\
\text { apoyada sobre su } \\
\text { amado?” }\end{array}$ \\
\hline $\begin{array}{l}\text { "é o selo do seu } \\
\text { coração" }\end{array}$ & 8.6 & $\begin{array}{l}\text { "Ponme como sello } \\
\text { sobre tu corazón" }\end{array}$ & “sello de su corazón” \\
\hline $\begin{array}{l}\text { “o amor é tão valente } \\
\text { como a própria morte” }\end{array}$ & 8.6 & $\begin{array}{l}\text { “porque fuerte } \\
\text { como la muerte } \\
\text { amor” }\end{array}$ & $\begin{array}{l}\text { "fuerte es como la } \\
\text { muerte el amor" }\end{array}$ \\
\hline
\end{tabular}

Como se puede observar, hicimos algunos ajustes por medio del recorte de "llena de delicias" (8.5), o del cambio del pronombre personal en "sello de su corazón", ya que los amantes en el texto se tratan de "usted" en castellano hasta ese momento. Hubo otro caso de referencia en que la cita no fue encontrada de manera textual, en "Temos às nossas portas toda casta de pombos...”, sino un versículo aproximado: "En nuestras puertas todas las frutas: las nuevas y las añejas, amado mío, he guardado para ti” (7.13). Para este caso específico, optamos por una traducción de lo escrito por Machado: "Tenemos a nuestras puertas toda casta de palomas...".

En la misma línea de la elección de obras contemporáneas al Siglo XIX para las citas intertextuales, usamos una traducción de Romeo and Juliet, publicada en 1872 en España, y realizada por Matías de Velasco y Rojas con el título Julieta y Romeo, ofrecida por el Centro Cultural Cervantes en su sitio web (SHAKESPEARE, 1872).

En otro orden de cosas, a partir de la decisión de traducir a la variante colombiana del castellano, buscamos mantener el tono del cuento por medio de las diferentes formas de tratamiento que el mismo utiliza. Así, usamos el tratamiento formal en tercera persona "mi señor” y “mi señora”, que mantiene la estructura del 
portugués. Igualmente, estimamos funcional al texto la presencia del pronombre "vós", que tradujimos por "vosotros", marcando las diferencias ya existentes en el texto de partida. La intención general fue, pues, mantener en la mayor medida posible el registro del texto, por medio de la flexibilidad del castellano para realizar este movimiento.

Otras decisiones fueron las relativas a mantener la grafía de los nombres en portugués, sin traducirlos; y la propensión a no usar palabras distintas del portugués cuando el castellano las tiene. De acuerdo con los significados de varias palabras en Colombia, mantuvimos "gimnasios y liceos", así como mantuvimos el verbo "andar", que podría haber sido traducido por "caminar"; y el "regalarse”, y no "deleitarse” o "regodearse". Por el contrario, no pudimos mantener "cochilar" como un verbo único, sino como "hacer la siesta”. Sí mantuvimos la expresión "Ni Corcovados, ni Himalayas valen mucha cosa al pie de tu cabeza, que los mide”, que bien podría ser traducida por "no valen mucho", pero que nos interesaba traer al castellano como una marca del portugués. Es destacable que usamos este principio en las dos ocasiones que aparece la expresión, a sabiendas del desliz semántico de la primera. Valoramos aquí la cadena significante instaurada en portugués: "Es para que no creas en las personas que van al Corcovado, y dicen que allá la impresión de la altura es tal, que el hombre queda siendo poca cosa. (...) Ni Corcovados, ni Himalayas valen mucha cosa al pie de tu cabeza, que los mide”.

Específicamente con relación a la variante que escogimos, cabe resaltar también nuestra decisión de traducir “poleiro” como “estaca”. Es preciso comentar que esta fue una de las decisiones que fueron objeto de más análisis, pues mientras que para una de nosotras la palabra "estaca” era absolutamente familiar en ese contexto, para la otra no representaba la posibilidad de exprimir el sentido de "poleiro" en el original. Así, traducido como "travesaño del gallinero" por Kovadloff y Gorga Filho, y como "varilla” por Cardellino, "poleiro” encontró en la economía de la variante que seleccionamos la opción de una traducción diferente. Se trata de un término ampliamente usado en Colombia para designar dicho objeto, registrado en refranes como "Cada loro en su estaca” y en numerosos textos literarios. Para ver un ejemplo del uso del término, veamos un fragmento de la crónica titulada "Los Cazadores”, de José Maria Córdovez Moure, publicada en la prensa alrededor de 1893, y posteriormente reunida en el libro Reminiscencias de Santafé y Bogotá:

En el Chaparral me regaló una hija de confesión la lora de siete colores que llevé al Guamo, y la puse en estaca junto a la iglesia: allí trabó amistad con el sacristán y los acólitos, de los que aprendió a rezar; pero el día menos pensado se presentaron otros loros, y mi lora se fue con ellos para no volver. (CÓRDOVEZ, 1962, p. 359; negritas nuestras)

Es necesario comentar también en esa perspectiva, la decisión que tomamos sobre la traducción de "juntinhos" como "junticos", pues, a pesar de que la forma del diminutivo más frecuente es la terminación "ito" - usada en las traducciones de Kovadloff, Gorga Filho y Cardellino -, en Colombia, Venezuela, Costa Rica y otros de los países caribeños, es más frecuente el uso de la terminación "ico(a)" en los casos de palabras cuya última sílaba comienza en "t”. Tal es el caso de palabras como "gato/gatico", "plato/platico" o "junto/juntico".

A modo de cierre, nos parece importante resaltar la importancia que tuvo, para el análisis de nuestra traducción, la lectura de las traducciones anteriores a las que tuvimos acceso. De esta manera, pudimos contrastar nuestras decisiones con las 
de aquellos traductores que nos antecedieron, y situarnos de acuerdo a nuestro momento histórico con relación a tal tradición. El contraste del trabajo de dichos traductores, además, permitió visualizar las pequeñas, pero significativas, diferencias que hay entre las distintas traducciones analizadas, sus lazos con las circunstancias que las originan, pero también su relativa independencia. Al situar nuestro proyecto de traducción en esa línea de traducciones, pudimos advertir cuán determinado está por el momento de relectura de la obra de Machado que vivimos en el Siglo XXI, y su dimensión en Latinoamérica, de donde provenimos y hacia donde traducimos.

Rosario Lázaro Igoa

rosilazaro@gmail.com

Doutoranda - Pós-graduação em Estudos da Tradução, Universidade Federal de Santa Catarina

Luz Adriana Sánchez Segura keuala2001@yahoo.com Doutoranda - Pós-graduação em Estudos da Tradução, Universidade Federal de Santa Catarina

\section{Referências}

BENJAMIN, W. "A tarefa do tradutor”. Traducción de Susana Kampff Lages. In: HEIDERMANN, W. Clássicos da teoria da tradução. Volume 1. AlemãoPortuguês. 2a ed. Florianópolis: UFSC, 2010. Pp. 202-233.

CORDOVEZ MOURE, J. M. Reminiscencias de Santafé y Bogotá. Madrid: Aguilar, 1962.

HALLEWELL, L. O livro no Brasil: (sua história). Traducción de Maria da Penha Villalobos, Lólio Lourenço de Oliveira y Geraldo Gerson de Souza. 2. ed. rev. y ampl. São Paulo: EDUSP, 2005.

MACHADO DE ASSIS, J.M. "El Canónigo ó Metafísica del Estilo”. Traducción de Rafael Mesa López. In: Varias historias. Paris: Garnier, 1911.

. "El canónigo; o, Metafísica del estilo". Sin datos de traductor. In: Varias historias. La Habana: Casa de las Américas, 1972.

"El canónigo o Metafísica del estilo". Traducción de Santiago Kovadloff. In: Cuentos. Prólogo y selección de Alfredo Bosi. Caracas: Ayacucho, 1985. p. 245-249.

"EL CANÓNIGO o Metafísica del Estilo". In: El alienista y otros cuentos. Prólogo de Ilán Stavans. México: Porrúa, 1993. p. 181-?

. "El canónigo o metafísica del estilo". Traducción de Remy Gorga Filho.

In: La iglesia del diablo y otros cuentos. Quito: Libresa, 2007. p. 139-146.

"El canónigo o Metafísica del estilo". Organización y traducción de Pablo Cardellino Soto. In: Varias historias. Montevideo: Cruz del Sur, 2012. p. 136-141. 
. “O Cônego ou Metafísica do Estilo”. [1885]. Edición disponible en: $<$ http://www.dominiopublico.gov.br/pesquisa/DetalheObraForm.do? select_action=\&co_obra=1983>[01/10/2013]

SHAKESPEARE, W. Julieta y Romeo. Traducción de Matías de Velasco y Rojas, Marqués de Dos Hermanas. Madrid: R. Berenguillo, 1872. Edición disponible en: $\quad<$ http://www.cervantesvirtual.com/obra-visor/julieta-y-romeo--0/html/> [01/10/2013] 